\title{
Factors Affecting Outcome in the Management of Peptic Perforation
}

\author{
Author \\ Dr Santosh Thorat \\ MBBS, MS (Surgery) FIAGES, Assistant professor of General Surgery, BJGMC \& SGH Pune \\ Dept of General Surgery, V S S Medical College Burla -768017 Sambalpur Odisha
}

\begin{abstract}
Perforated peptic ulcer is one of the commonest surgical emergencies. Advanced age, preoperative shock, coexisting medical illness and delay in treatment are common risk factors associated with increased mortality and morbidity. Hence patients should be assessed and treated early. The present study is carried out in respect to the above critical and prognosis bearing factor. 380 cases of perforated peptic ulcer admitted to V.S.S. Medical College Hospital, Burla were studied from September, 2010 to August, 2012. Those cases that were lost to follow up were excluded from the study.
\end{abstract}

Keywords: PEPTIC perforation. perforated peptic ulcer

\section{Introduction}

Duodenal ulcer perforations are a common cause of peritonitis. The classic, pedicled omental patch that is performed for the 'plugging' of these perforations was first described by Cellan-Jones in 1929 , although it is commonly, and wrongly attributed to Graham, who described the use of a free graft of the omentum to repair the perforation in 1937 .

H.pylorii infection of gastric mucosa has an important role in the pathogenesis of duodenal ulcer disease and is of particular importance in recurrent or intractable ulcer disease. Little is known about the role of H.pylori infection in perforated peptic ulcer disease and its recurrence. Since the late 1980s, laparoscopy has become increasingly popular. The benefits of laparoscopy with regard to the acute abdomen as a diagnostic tool have been established since and also its therapeutic possibilities seem to be advantageous.
The rapid development of laparoscopic surgery has further complicated the issue of the best approach for the management of perforated peptic ulcer (PPU). PPU is a condition in which laparoscopic repair is an attractive option. Not only is it possible to identify the site and pathology of the perforation, but the Procedure also allows closure of the perforation and peritoneal lavage, just like in open repair but without a large upper abdominal incision. Nonetheless, not all patients are suitable for laparoscopic repair.

Despite many trials (mostly nonrandomized or retrospective), the routine treatment for perforated peptic ulcer still seems to be by upper laprotomy.

\section{Materials \& Methods}

This study has been taken up on the cases of perforated peptic ulcer that have been admitted to from casualty, surgical O.P.D. and also on 
perforation that arisen as a complication while the patient was in the hospital for surgical treatment of peptic ulcer or taking medicinal treatment in medical ward. The patients who were operated for some other indication and found to have peptic perforation were also included in the study. A prospective review was made in all charts of parameters between the period September, 2010 to August, 2012. After admission, detailed history was elicited from the patient and a thorough clinical examination was done to exclude other acute abdominal conditions and the available investigations like plain X ray abdomen with erect posture showing both domes of diaphragm and four quadrant peritoneal tap were done to approach at the diagnosis. Long term follow up was done and the patients lost to follow up were excluded from the study.

\section{Preoperative measures}

After assessing the patient, early resuscitation was done by intravenous infusion depending on individual care. Nasogastric aspiration and a broad spectrum antibiotic were started. All patients received an injection of $0.5 \mathrm{ml}$ of Tetanus toxoid on admission. The condition of the patient was reviewed at frequent intervals.

\section{Operative findings}

After the patient was fully resuscitated, laparotomy was done by an upper midline or right upper paramedian incision under general /spinal anaesthesia and the time of operation and operative findings were noted.

1. Peritoneal contents

- Bilious

- Fibrinous flecks

- Food particles

- Pus

2. Characteristics of the ulcer

- Site: The term duodenal ulcer perforation is here used to include, in addition to duodenal ulcer, those perforated ulcers just proximal to the duodenum in the pylorus and distal antrum. The exact anatomical location of perforation in this area relative to pylorus is difficult to ascertain because of the pathological changes usually present.

- Size

- Sealed or not

- Associated pathology in the form of bleeding, stenosis or malignancy

\section{Procedure}

Except very few critically ill patients, almost all the cases were exposed for surgical treatment. In patients undergoing surgery perforation was closed with sutures (vicryl 2-0 and Atraumatic chromic catgut 1-0) followed by omental patch. Primary definitive surgery (in the form of TV+GJ alone) was done in selected cases according to the following criteria.

- Patients fit to undergo a major surgical procedure

- No frank pus in the peritoneum on laparotomy

- Patients with outlet obstruction or in whom closure of perforation was to produce obstruction

- Evidence of chronic duodenal ulcer in the form of perforation history of ulcer dyspepsia of more than 3 months and/or fibrosis and scarring in pyloroduodenal region.

Thorough peritoneal toileting was done and flank drainage in form of abdominal drain was given in all cases.

\section{Post-operative management}

Patients were watched for recovery from anaesthesia and all vitals were recorded at frequent intervals. Intravenously fluids were given according to requirement of the patients and antibiotics eg. Ciprofloxacin and metronidazole started. Frequent Ryles tube aspiration was done to decompress the upper G.I. tract. Ryles tube was removed and oral fluids encouraged on return of bowel sounds usually after 48-72 hrs. Drain was removed on $4^{\text {th }}$ post-operative day (except in those 
who developed biliary leakage). Patients were encouraged for ambulation and respiratory exercise. Any complications during this period was recorded and managed accordingly. After removal of stitches patients were discharged if found fit with the advice to attend clinic for follow up.

\section{Follow up}

All cases were followed up till date at varying intervals and patients lost to follow up were excluded from the study.

\section{Observation}

The present study was conducted on 380 patients of perforated peptic ulcer admitted to V.S.S. Medical College Hospital, Burla. The observations made were recorded in the following manner.
In our series of 380 cases the highest incidence of peptic perforation was in the age group of 31-40 yrs, being 112 (29.47\%); next was in the age group 41-50 yrs, being 88 (23.15\%) and third was 21-30 yrs i.e.56 (14.73\%).

Mortality increases with increasing age i.e. $7.1 \%$ in $41-50$ yrs Age group to $22.22 \%$ in $61-70$ yrs age group and $88 \%$ above 70 yrs of age.

In our series, out of total 380 cases $332(87.36 \%)$ were males and $48(12.63 \%)$ were females and female mortality (6 out of $48(12.5 \%$ ) is more than male mortality [29 out of 332] ( $8.73 \%)$.

The highest incidence was recorded in the poor socio-economic status group $(69.2 \%)$.

Previous history of peptic ulcer ranging from $11 \mathrm{yrs}$ to $50 \mathrm{yrs}$ was present in 217 cases $(57.10 \%)$ in this study. 163 patients $(42.89 \%)$ had no previous ulcer history.

\section{Distribution Of Time Interval Between Perforation And Operation, And Its Effect On Mortality}

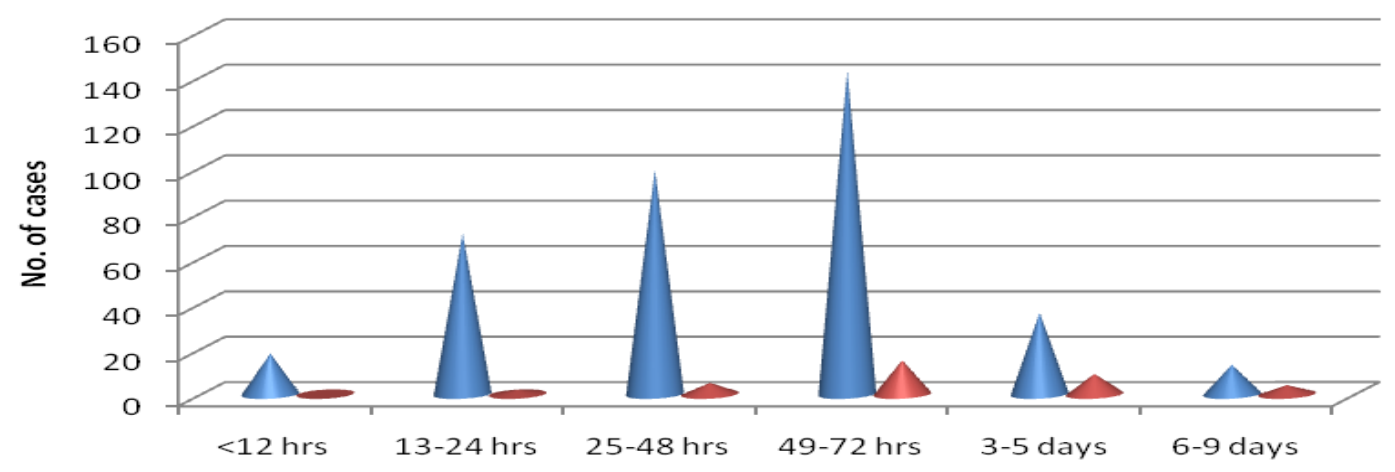

Time Interval

No. of patients No. of deaths

In our study in majority $(63.65 \%)$ of the patients duration of perforation ranged from 25-72 hrs. This delay in presentation affects the ultimate outcome. There was no death within $12 \mathrm{hrs}$ and after that mortality rate increased steadily to attain $30.7 \%$ by $6-9$ days.

Plain X-Ray abdomen was taken in erect posture prior to operation to confirm the diagnosis. Gas was present under one or both domes of diaphragm in $339(89.21 \%)$ cases. In rest 41 $(10.18 \%)$ cases no free gas under diaphragm was seen.
In our series 168 patients were subjected to laparotomy. Two cases were treated conservatively who ultimately died.

\section{Table Showing Site Of Perforation}

\begin{tabular}{|l|l|l|}
\hline Site of perforation & No. of cases & Percentage \\
\hline Duodenum & 343 & 91.46 \\
\hline Pyloric region & 32 & 8.52 \\
\hline
\end{tabular}

In 343 cases $(91.46 \%)$ perforation gas present in the first part of duodenum (anterior or superior wall). 32 cases $(8.52 \%)$ had perforation in the pyloric region. 
Out of the 375 cases undergoing laparotomy 9 cases had sealed perforation, so size could not be assessed. Majority 309 (82.11\%) had perforation size ranging from $3-10 \mathrm{~mm}$. $57(15.2 \%)$ cases had perforation size more than $10 \mathrm{~mm}$. Maximum size of perforation which was observed in our series was $16 \mathrm{~mm}$.

Table Showing Size Of Perforation And Related Mortality \& Morbidity

\begin{tabular}{|l|l|l|l|l|l|}
\hline \multirow{2}{*}{$\begin{array}{l}\text { Size of } \\
\text { perforation }\end{array}$} & $\begin{array}{l}\text { No. of } \\
\text { cases }\end{array}$ & \multicolumn{2}{|l|}{ Death } & \multicolumn{2}{|l|}{$\begin{array}{l}\text { Post-operative } \\
\text { complication }\end{array}$} \\
\cline { 3 - 6 } & & $\begin{array}{l}\text { No. of } \\
\text { cases }\end{array}$ & Percentage & $\begin{array}{l}\text { No. of } \\
\text { cases }\end{array}$ & Percentage \\
\hline $1-5 \mathrm{~mm}$ & 156 & 7 & 4.48 & 70 & 44.81 \\
\hline $6-10 \mathrm{~mm}$ & 153 & 15 & 9.8 & 76 & 49.67 \\
\hline$>10 \mathrm{~mm}$ & 57 & 8 & 14.02 & 35 & 61.40 \\
\hline Sealed & 9 & -- & -- & -- & -- \\
\hline
\end{tabular}

Mortality and immediate post operative morbidity in the form of complication and hospital stay ( $>14$ days) increased with increase in diameter of perforation. Mortality and morbidity ranged from $4.48 \%$ and $44.87 \%$ in cases of perforation of $1-5$ $\mathrm{mm}$ diameter to $14.02 \%$ and $61.40 \%$ in perforation more than $10 \mathrm{~mm}$ diameter respectively. This association may not be absolute because other factors like age, duration of perforation, preoperative shock, medical illness also come into play.

Out of the total 380 patients $98(25.78 \%)$ patients had preoperative shock. In our series 35 patients who died, all of them had preoperative shock $(35.71 \%)$.

\section{Number Of Cases Treated By Different Methods And The Mortality}

\begin{tabular}{|l|l|l|l|l|}
\hline Treatment & No. of cases & Percentage & Mortality & Percentage \\
\hline Closure + TV \& GJ & 4 & 1.05 & --- & --- \\
\hline Closure + GJ & 9 & 2.36 & 2 & 22.22 \\
\hline Closure only & 353 & 92.89 & 28 & 7.93 \\
\hline Toileting only & 9 & 2.36 & --- & --- \\
\hline Conservative & 5 & 1.13 & 5 & $100 \%$ \\
\hline TOTAL & 380 & & 35 & \\
\hline
\end{tabular}

In our series only five cases $(1.13 \%)$ were treated conservatively. Due to severe degree of shock and associated medical illness, five patients died within 24 hrs of presentation to hospital.

Four types of operative procedure were employed in rest $375(98.8 \%)$ cases.

In $9(2.36 \%)$ cases only toileting was done as the perforation was sealed. There was no mortality.

There were 35 deaths and all of them had preoperative shock. 13 cases had coexisted cardiovascular, 13 had respiratory and 9 had both cardiovascular and respiratory disease.

Wound infection was the most common postoperative complication, less common were diarrhoea, biliary fistula and fever>3days. None of the patients developed fatal complication like mediastinitis.

Overall mortality was $9.21 \%$.

The mortality and morbidity were high in elderly patients, patients having long duration of perforation, increased diameter of perforation, patients with preoperative shock and coexisting medical illness.

The status of the operating surgeon had no impact on the outcome.

The average duration of hospital stay was 14 days in those treated with simple closure and 11.7 days in those treated by definitive surgery. 
In the group of patients undergoing simple closure 92 had unsatisfactory results (recurrence of ulcer symptoms, haematemesis and pyloric stenosis) out of which 17 required subsequent definitive surgery. In the definitive surgery group, all are asymptomatic till date.

\section{Conclusion}

Perforated peptic ulcer is one of the commonest surgical emergencies. Advanced age, preoperative shock, coexisting medical illness and delay in treatment are common risk factors associated with increased mortality and morbidity. Hence patients should be assessed and treated early.

Polybacterial flora is associated with higher mortality, hence in all cases higher antibiotics should be started. After adequate preoperative resuscitation those patients who were otherwise fit should be exposed to surgery. Since primary definitive surgery is not associated with increased mortality and morbidity it should be considered in fit patients with definite past history of peptic ulcer, past history of other complications of peptic ulcer, patients perforated on medical treatment and large perforations. This also saves a second ulcer cure surgery, expense and manpower in these patients. Simple closure of perforation with through toileting \& drainage of peritoneal cavity should be done in whom definitive surgery is contraindicated, and if surgeon is not experienced. Patients undergoing simple closure should receive full dose of Proton pump inhibitors which are very cost effective until endoscopic proof of healing is obtained and then maintenance therapy for further 2-3 months. But attempt should be made to go for definitive surgery in one setting if conditions are favourable.

\section{Bibliography}

1. Agresta F, Mazzarolo G, Ciardo LF, Bedin $N$ (2008) The laparoscopic approach in abdominal emergencies: has the attitude changed? A single-center review of a 15- year experience. Surg Endosc 22:12551262

2. Ates M, Coban S, Sevil S, Terzi A (2008) The efficacy of laparoscopic surgery in patients with peritonitis. Surg Laparosc Endosc Percutan Tech 18:453-456

3. Sanabria AE, Morales $\mathrm{CH}$, Villegas $\mathrm{MI}$ (2005) Laparoscopic repair for perforated peptic ulcer disease. Cochrane Database Syst Rev CD004778

4. Lagoo S, McMahon RL, Kakihara M, Pappas TN, Eubanks S (2002) The sixth decision regarding perforated duodenal ulcer. JSLS 6:359-368

5. Lau WY (2002) Perforated peptic ulcer: open versus laparoscopic repair. Asian J Surg 25:267-269

6. Druart ML, Van Hee R, Etienne J, Cadie're GB, Gigot JF, Legrand $M$, Limbosch JM, Navez B, Tugilimana M, Van Vyve E, Vereecken L, Wibin E, Yvergneaux JP (1997) Laparoscopic repair of perforated duodenal ulcer. A prospective multicenter clinical trial. Surg Endosc 11:1017-1020

7. Regression of fundic gland polyps following acquisition of H.pylorii infection, case report, N. Warantabe, Gut 2002,51:742-745.

8. Cellan-Jones CJ: A rapid method of treatment in perforated duodenal ulcer. BMJ 1929, 36:1076-7.

9. Ananthakrishnan N, Anganu K. Is ulcer recurrence after simple closure of perforated duodenal ulcer predictable ? Ind. J. Gastroent $12:$ 80, 1993.

10. Barksdale A R, Schwartz R W. Current management of perforated peptic ulcer. Curr Surg 2000; 57: 594-599.

11. Bhogal RH, Athwal R, Durkin D, Deakin $\mathrm{M}$, Cheruvu CN. Comparison between open and laparoscopic repair of perforated peptic ulcer. World J.Surg.2008 Nov;32 (11):2371-4. 